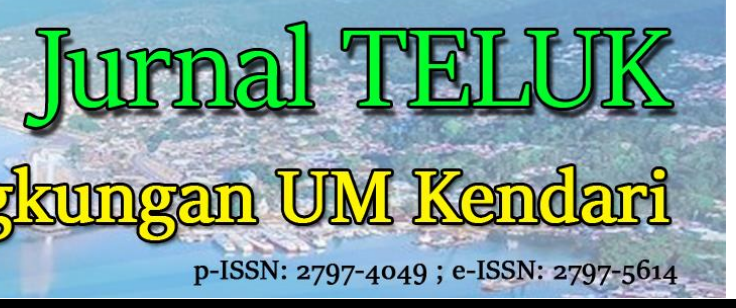

Artikel Penelitian

\title{
Evaluasi Teknik Operasional dari Kinerja Instalasi Pengolahan Lumpur Tinja di Kota Kendari
}

\author{
Renaldo Rasawula Lukman ${ }^{a}$, Yunita Eka Pratiwi ${ }^{a}$, dan Rosdiana ${ }^{a *}$ \\ ${ }^{a}$ Program Studi Teknik Lingkungan, Fakultas Teknik, Universitas Muhammadiyah Kendari, Indonesia.
}

\section{INFORMASI ARTIKEL}

Sejarah Artikel:

Diterima Redaksi: 1 Mei 2021

Revisi Akhir: 15 Mei 2021

Diterbitkan Online: 1 Juni 2021

\section{KATA KUNCI \\ Feces Mud, Kendari City, Treatment, \\ Wastewater}

\section{KORESPONDENSI}

Telepon: +62852-4261-1896

E-mail: rosdiana@gmail.com

\section{PENDAHULUAN}

Instalasi Pengolahan Lumpur Tinja (IPLT) adalah instalasi pengolahan air limbah yang dirancang hanya menerima dan mengolah lumpur tinja yang akan diangkut melalui mobil (truk tinja). Pengolahan lumpur tinja di IPLT merupakan pengolahan lanjutan karena lumpur tinja yang telah diolah di tangki septik belum layak dibuang di media lingkungan. Lumpur tinja yang terakumulasi secara reguler dikuras atau dikosongkan kemudian diangkut ke IPLT dengan menggunakan truk tinja. IPLT merupakan salah satu upaya terencana untuk meningkatkan pengolahan dan pembuangan limbah yang ramah lingkungan.

Limbah tinja membutuhkan pengolahan apabila ternyata mengandung senyawa pencemar yang berakibat menciptakan kerusakan terhadap lingkungan atau berpotensi menciptakan pencemaran. Suatu perkiraan harus dibuat lebih dahulu dengan mengidentifikasikan sumber pencemaran, sistem pengolahan, banyaknya buangan dan jenisnya, serta kegunaan bahan beracun dan berbahaya yang terdapat dalam pabrik (Ginting, 2007). Oleh karena itu, dibutuhkan sebuah evaluasi kinerja pada IPLT tersebut untuk mengoptimalkan kinerja dari IPLT untuk mendapatkan hasil buangan yang memenuhi standar baku air limbah domestik No. 05 Tahun 2014. Kualitas limbah menunjukkan spesifikasi limbah yang diukur dari jumlah kandungan bahan pencemar di dalam limbah yang terdiri dari berbagai parameter. Semakin kecil jumlah parameter dan konsentrasinya, menunjukkan semakin kecilnya peluang untuk terjadinya pencemaran lingkungan (Kristanto, 2004).

Air limbah tinja banyak mengandung nutrien yang dapat merangsang pertumbuhan mikroorganisme dengan komposisi air limbah pada umumnya 99,9\% air dan $0,1 \%$ padatan. Padatan yang terdapat dalam limbah cair terdiri dari $70 \%$ padatan organik dan 30\% padatan non-organik (Sugiharto, 1987). Limbah lumpur tinja jika tidak diolah dengan benar dapat menghasilkan kontaminan yang berpotensi mencemari badan air dan belum memenuhi standar baku mutu air karena masih mengandung kadar BOD, COD, TSS, pH, minyak dan lemak, serta Escherichia Coli yang masih tinggi. Menurut Moertinah (2010), kandungan BOD yang tinggi dapat menyebabkan turunnya oksigen perairan, 
keadaan anaerob (tanpa oksigen), sehingga dapat mematikan ikan dan menimbulkan bau busuk.

Instalasi pegolahan lumpur tinja Kota Kendari melayani pengolahan lumpur tinja seluruh kecamatan dengan sumber yang berasal dari unit pengelolah limbah domestik dan fasilitas komersil (hotel, ruko, dan lain-lain). Penyedotan lumpur tinja hanya dilakukan oleh 3\% dari total keseluruhan unit septik tank yang harus disedot. Septik tank wajib sedot merupakan septik tank yang sudah digunakan selama lebih dari 2 tahun. Kota kendari memiliki 2 unit mobil tinja yang beroperasi setiap hari untuk melayani penyedotan lumpur tinja yang berasal dari domestik dan komersial. Selain itu juga mobil tinja melayani hingga kabupaten lain.

Semakin bertambahnya jumlah penduduk Kota Kendari setiap tahunnya, maka limbah yang dihasilkan juga akan semakin besar dengan pertimbangan bahwa di Kota Kendari hanya memiliki 1 Unit Instalasi Pengolahan Lumpur Tinja (IPLT) yang melayani semua kecamatan. Dari uraian di atas penulis tertarik untuk mengevaluasi kinerja Instalasi Pengolahan Lumpur Tinja (IPLT) Kota Kendari.

\section{METODOLOGI}

\subsection{Tempat dan Waktu Penelitian}

Penelitian ini di lakukan di Instalasi Pengolahan Lumpur Tinja (IPLT) Kota Kendari yang bertempat di Kelurahan Watulondo, Kecamatan Puuwatu, Kota Kendari. Waktu penelitian dilaksanakan pada Bulan Maret - Mei 2020.

\subsection{Populasi dan Sampel}

\subsubsection{Populasi}

Populasi dalam penelitian ini adalah air limbah dan unit Instalasi Pengolahan Lumpur Tinja (IPLT) Kota Kendari.

\subsubsection{Sampel}

Sampel dalam penelitian ini adalah air limbah sebelum pengolahan dan sesudah melewati IPLT dan keseluruhan unit IPLT.

\subsubsection{Jenis dan Sumber Data}

Menurut Leedy (1980), data diklasifikasikan dalam tiga bentuk berdasarkan sumber perolehannya yaitu :

\section{Data Primer}

Data primer merupakan sumber data yang diperoleh langsung dari sumber dengan cara :

a. Observasi lapangan.

b. Kondisi eksisting Instalasi Pengolahan Lumpur Tinja Kota Kendari.

c. Sampel lumpur tinja Kota Kendari.

2. Data Sekunder

a. Data topografi.

b. Data jumlah penduduk Kota Kendari.

c. Data cakupan layanan Instalasi pengolahan Lumpur Tinja kota Kendari, dan lain-lain.

\section{Pengolahan Data}

Data diperoleh dari proses pengumpulan data dan hasil analisis laboratorium untuk mengetahui kualitas limbah.

\subsubsection{Cara Pengumpulan Data}

Pengumpulan data diperoleh melalui :

1. Kajian Lapangan

Kajian lapangan dilakukan dengan cara observasi langsung ke Instalasi Pengolahan Lumpur Tinja untuk memperoleh data-data yang dibutuhkan. Salah satu cara pengumpulan data dilapangan adalah dengan melakukan pengambilan sampel air limbah untuk mengukur parameter BOD, COD, TSS, pH, minyak dan lemak, serta Escherichia Coli.

2. Analisis Laboratorium

Analisis laboratorium dilakukan di Laboratorium Dinas Kesehatan Provinsi Sulawesi Tenggara untuk mengetahui parameter BOD dan minyak.

\subsubsection{Prosedur Kerja}

Prosedur kerja pada penelitian ini adalah sebgai berikut :

1. Ide Penelitian

2. Mencari literatur tentang Instalasi Pengolahan Lumpur Tinja (IPLT)

3. Pengumpulan data yang terdiri dari :

a. Data primer (survey lokasi penelitian)

b. Data sekunder (data penunjang dari buku dan internet)

4. Pengambilan sampel lumpur tinja

5. Uji laboratorium untuk mengetahui kadar BOD serta minyak dan lemak setelah masuk pengolahan.

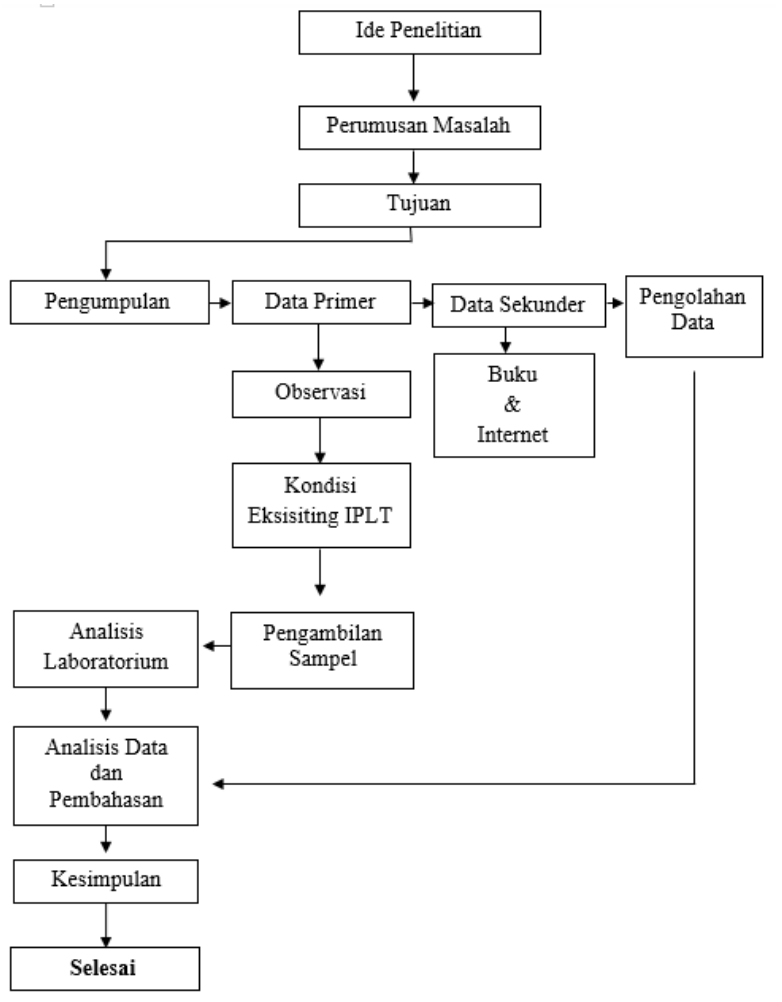

Gambar 1. Diagram Alir Penelitian 


\section{HASIL DAN PEMBAHASAN}

\subsection{Gambaran Umum Lokasi}

IPLT Puulongdiga Kota Kendari dibangun pada tahun 2006 dan mengalami relokasi/pembangunan baru pada tahun 2010 dan 2018. Berlokasi di Kelurahan Watulondo Kecamatan Puuwatu Kota Kendari, berjarak $\pm 10 \mathrm{Km}$ dari pusat Kota Kendari. Lokasi IPLT Puulongdiga Kota Kendari dapat dilihat pada Gambar 2 berikut.

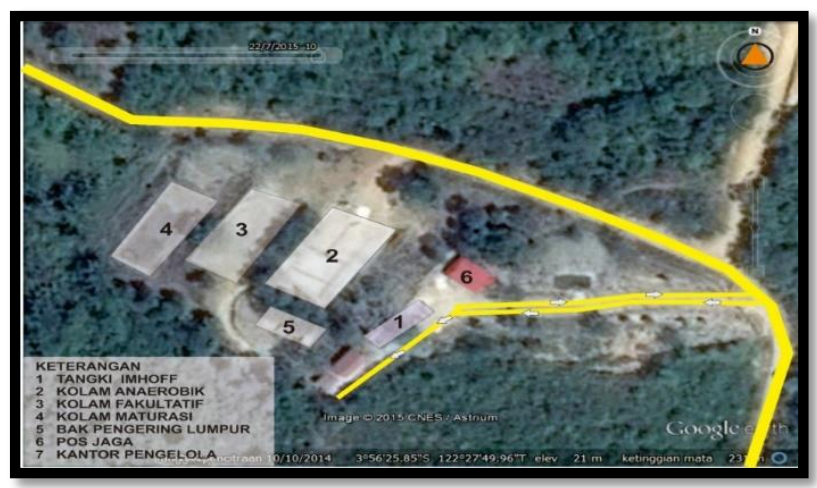

Gambar 2. Lokasi Penelitian

IPLT Kota Kendari melayani pengolahan lumpur tinja seluruh kecamatan dengan sumber yang berasal dari unit pengolahan limbah domestik dan fasilitas komersil (hotel, ruko dan lain-lain). Peta cakupan layanan IPLT dapat dilihat pada Gambar 3.

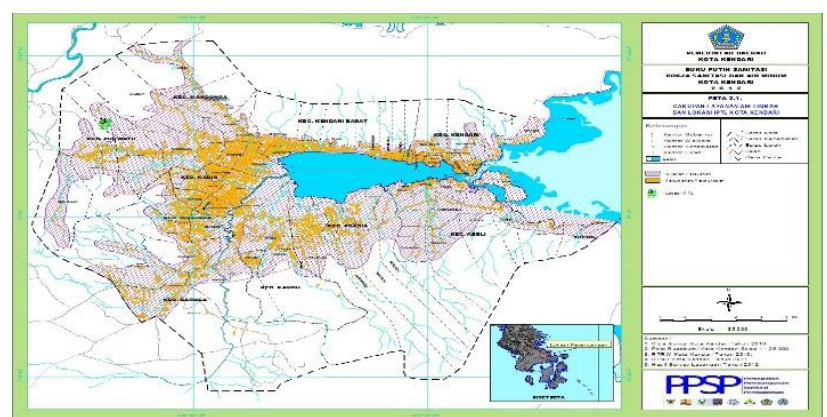

Gambar 3. Cakupan Layanan IPLT Kota Kendari

IPLT Kota memiliki fasilitas berupa bak penampung, tangki imhoff, kolam anaerobik dan kolam fakultatif, kolam maturasi, bak pengering lumpur, kemudian untuk fasilitas penunjang ada pos jaga dan kantor pengelola. Sarana ini juga dilengkapi dengan 2 unit mobil tinja yang beroperasi di bawah Dinas Pekerjaan Umum Kota Kendari yang sebelumnya penanganan lumpur tinja berasal dari Dinas Lingkungan Hidup dan Kehutanan.

\subsection{Parameter Limbah Cair}

Parameter Pengolahan Lumpur Tinja Kota Kendari dapat diketahui melalui pengujian sampel air limbah di Balai Laboratorium Kesehatan Kendari untuk mengetahui kandungan pencemarnya. Sesuai Peraturan Menteri Lingkungan Hidup Republik Indonesia. Adapun kualitas Pengolahan Lumpur Tinja Kota Kendari dapat dilihat pada Tabel 1.

Tabel 1. kualitas Pengolahan Lumpur Tinja Kota Kendari

\begin{tabular}{cccccc}
\hline No. & Parameter & Satuan & Hasil Pemeriksaan & Baku Mutu & Spesifikasi Metode \\
\hline 1 & Biologycal Oxygen Demand (BOD) & $\mathrm{mg} / \mathrm{L}$ & 125,1 & 100 & BOD meter \\
2 & Minyak dan Lemak & $\mathrm{mg} / \mathrm{L}$ & 1 & 10 & Gravimetri \\
\hline
\end{tabular}

Berdasarkan hasil pengujian Parameter Pengolahan Lumpur Tinja Kota Kendari yang telah dianalisis di Balai Laboratorium Kesehatan Kendari menyatakan bahwa kandungan Biologycal Oxygen Demand (BOD) pada Lumpur Tinja Kota Kendari masih diatas ambang baku mutu yaitu sebesar $125,1 \mathrm{mg} / \mathrm{L}$ sedangkan kandungan minyak dan lemak masih memenuhi standar baku mutu yang telah ditetapkan berdasarkan Peraturan Menteri Lingkungan Hidup No. 05 Tahun 2014 yaitu sebesar 1 mg/l.

\subsection{Aspek Teknis}

\subsubsection{Teknologi}

IPLT Kota Kendari menggunakan teknologi pengolahan berupa sistem kolam yang terdiri dari tangki imhoff, kolam anaerobik, kolam fakultatif, kolam maturasi dan bak pengering lumpur. Semua unit pengolah lumpur tinja berjumlah 1 unit. Diagram alir IPLT Kendari dapat dilihat pada Gambar 3. Lumpur tinja dari unit pengolah air limbah diangkut dengan menggunakan mobil tinja yang kemudian dimasukan ke tangki imhoff. Di dalam tangki imhoff terjadi pemisahan antara zat padat dan cair yang terdapat dalam lumpur tinja. Padatan dialirkan menuju bak pengering lumpur sedangkan cairan dialirkan ke kolam anaerobik yang kemudian diteruskan ke kolam fakultatif dan kolam maturasi. Aliran dalam sistem ini mengalir secara gravitasi.

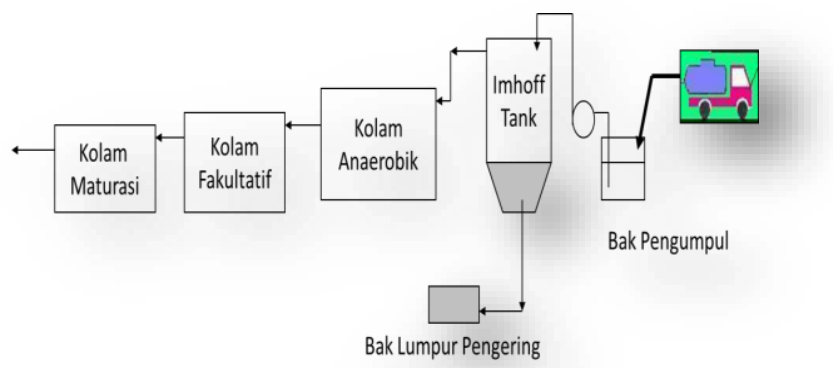

Gambar 3. Diagram Alir IPLT Kendari

\section{a. Tangki Imhoff}

Tangki imhoff terdiri dari 2 kompartemen yaitu kompartemen atas berfungsi sebagai ruang pengendap dan kompartemen bawah sebagai ruang pencerna, sehingga bagian lumpur tinja yang berupa padatan akan mengendap di bagian kompartemen bawah dan tinggal selama beberapa bulan namun tetap memerlukan pengurasan secara berkala 
yang selanjutnya dapat dikeringkan pada unit pengering lumpur.

Berdasarkan petunjuk teknis IPLT Departemen PU 1998 mengenai tata cara perencanaan IPLT sistem kolam dengan sistem kolam terdapat beberapa kriteria untuk tangki imhoff. Jika dibandingkan dengan kriteria maka dapat diketahui terdapat beberapa hal tidak sesuai antara kondisi eksisting tangki imhoff IPLT Kendari dengan kriteria yang dipersyaratkan antara lain:

1. Tinggi tangki imhoff hanya $3,7 \mathrm{~m}$ (kriteria $6-9 \mathrm{~m}$ ).

2. Perbandingan lebar dan panjang tangki hanya $1: 1,67$ (kriteria 1:2).

3. Syarat kemiringan penampung lumpur, minimal 30 tidak terpenuhi.

Perbandingan tangki imhoff eksisting dengan kriteria tangki imhoff dapat dilihat pada Gambar 4.

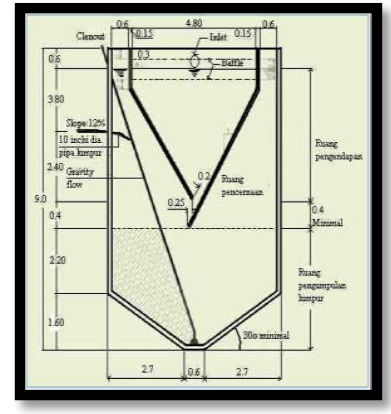

Kriteria Imhoff

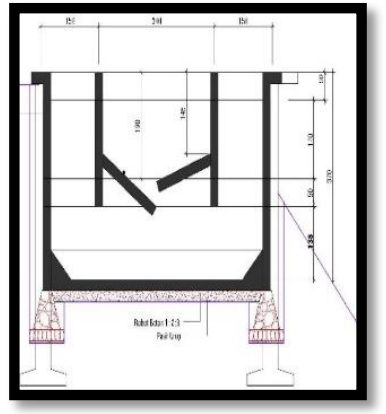

Imhoff Eksisting
Gambar 4. Perbandingan Tangki Imhoff Eksisting dengan Imhoff Kriteria

Kelebihan dan kelemahan tangki imhoff Kota Kendari dapat dilihat pada Tabel 2 .

Tabel 2. Kelebihan dan kelemahan tangki imhoff Kota Kendari

\section{Kelebihan}

Kondisi bangunan dalam kondisi baik

- Operasi dan pemeliharaan mudah sehingga dapat menggunakan sumber daya manusia dengan pengetahuan minimal.

\section{Kekurangan}

\begin{tabular}{|c|c|}
\hline $\begin{array}{l}\text { - Operasi dan pemeliharaan mudah } \\
\text { sehingga dapat menggunakan sumber daya } \\
\text { manusia dengan pengetahuan minimal. }\end{array}$ & $\begin{array}{l}\text { - Jika tidak dioperasikan dan dirawat dengan baik, maka resiko } \\
\text { penyumbatan pada pipa pengaliran } \\
\text { - Membutuhkan pengolahan lebih lanjut untuk efluen baik pada } \\
\text { frasa cair maupun padatan yang telah dipisahkan } \\
\text { - Efisiensi penyisihan rendah } \\
\text { - Pinggiran kolam stabilisasi ditumbuhi tanaman liar permukaan } \\
\text { Sludge Drying Bed (SDB) ditumbuhi tanaman liar. }\end{array}$ \\
\hline
\end{tabular}

Tabel 3. Kelebihan dan kelemahan kolam anaerobik Kota Kendari

\begin{tabular}{ll}
\hline \multicolumn{1}{c}{ Kelebihan } & \multicolumn{1}{c}{ Kelemahan } \\
\hline $\begin{array}{l}\text { Mengurangi penumpukan lumpur pada unit } \\
\text { pengolahan berikutnya. }\end{array}$ & Menimbulkan bau yang dapat mengganggu \\
$\begin{array}{l}\text { Biaya operasional murah. } \\
\begin{array}{l}\text { Mampu menerima limbah dengan } \\
\text { konsentrasi yang tinggi. }\end{array}\end{array}$ & Proses degradasi berjalan lambat \\
\hline
\end{tabular}

\section{b. Kolam Anaerobik}

Kolam anaerobik merupakan unit pengolah BOD dengan kondisi tanpa oksigen/anaerob. Kolam anaerobik yang terdapat di IPLT Kendari memiliki kedalaman yang sesuai dengan kriteria desain. Kedalaman kolam anaerobik eksisting hanya 2,0 $\mathrm{m}$, hal ini menjadikan kolam tersebut sebagai kolam anaerob. Pada petunjuk teknis perencanaan IPLT sistem kolam, kolam anaerobik disyaratkan dirancang dengan kedalaman 2-4 m dengan tujuan untuk membentuk dan mempertahankan kondisi anaerobik bagi proses degradasi oleh mikroba yang terjadi didalamnya. Potongan kolam anaerobik IPLT Kota Kendari dapat dilihat pada Gambar 5.

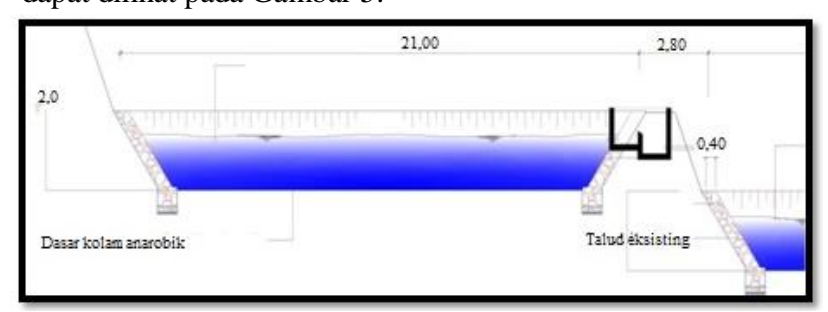

Gambar 5. Potongan Kolam Anaerobik IPLT Kendari
Kriteria desain lain untuk kolam anaerobik berdasarkan Departemen PU, 1998 yaitu:

- Rasio panjang banding lebar sebesar (2-4):1.

- Kolam anaerobik umumnya diaplikasikan 2 (dua) unit kolam yang dibuat paralel atau seri agar dapat mengantisipasi jika ada perawatan kolam.

- Kolam diberi talud sebesar 1:3 untuk memudahkan perawatan kolam.

Kelebihan dan kelemahan kolam anaerobik Kota Kendari dapat dilihat pada Tabel 3 .

\section{c. Kolam Fakultatif}

Kolam fakultatif berfungsi untuk menguraikan dan menurunkan konsentrasi bahan organik yang ada di dalam limbah yang telah diolah pada kolam anaerobik. Proses yang terjadi pada kolam ini adalah campuran antara proses anaerob dan aerob. Secara umum kolam fakultatif terstratifikasi menjadi tiga zona atau lapisan yang memiliki kondisi dan proses degradasi yang berbeda. Kriteria desain lain untuk kolam anaerobik berdasarkan Departemen PU, 1998 yaitu :

1. Tinggi air eksisting 2,0 $\mathrm{m}$ (kriteria 1,2 -2,4 m).

2. Tinggi jagaan $0,5 \mathrm{~m}$ (kriteria $0,3-0,5 \mathrm{~m}$ ). 


\section{Rasio $(\mathrm{P}=\mathrm{L}) 2: 4: 1$}

Potongan Kolam Fakultatif IPLT Kendari dapat dilihat pada Gambar 6.

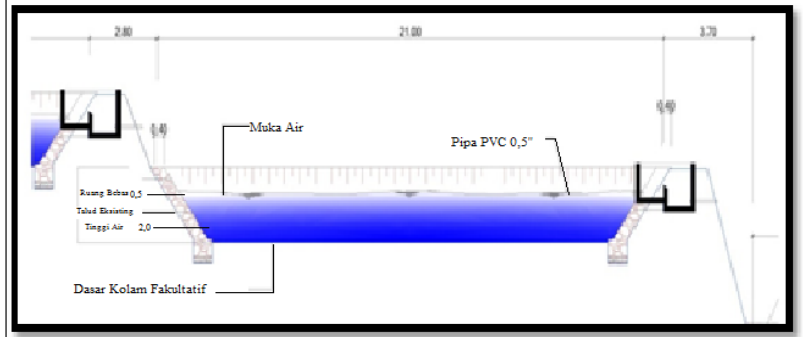

Gambar 6. Potongan Kolam Fakultatif IPLT Kendari

Kelebihan dan kelemahan kolam fakultatif Kota Kendari dapat dilihat pada Tabel 4.

Tabel 4. Kelebihan dan kelemahan kolam fakultatif Kota Kendari

\begin{tabular}{|c|c|}
\hline Kelebihan & Kelemahan \\
\hline $\begin{array}{l}\text { - Mampu menghadapi } \\
\text { beban yang berfluktuasi. }\end{array}$ & $\begin{array}{l}\text { - Jika tidak dirawat dengan } \\
\text { baik, maka kolam dapat } \\
\text { menjadi sarang bagi } \\
\text { serangga. }\end{array}$ \\
\hline $\begin{array}{l}\text { - Operasi dan perawatan } \\
\text { mudah sehingga tidak } \\
\text { memerlukan keahlian } \\
\text { tinggi. }\end{array}$ & $\begin{array}{l}\text { - Berpotensi mengeluarkan } \\
\text { bau. }\end{array}$ \\
\hline $\begin{array}{l}\text { - Biaya operasi dan } \\
\text { perawatan murah. }\end{array}$ & $\begin{array}{l}\text { - Memerlukan pengolahan } \\
\text { lanjutan terutama akibat } \\
\text { pertumbuhan algae pada } \\
\text { kolam. }\end{array}$ \\
\hline
\end{tabular}

\section{d. Kolam Maturasi}

Fungsi utama kolam maturasi adalah menghilangkan mikroba patogen yang berada di dalam limbah melalui perubahan kondisi yang berlangsung cepat dan $\mathrm{pH}$ yang sangat tinggi (Direktorat PPLP). Kedalaman kolam yang disyaratkan dalam petunjuk teknis perencanaan IPLT adalah $0.8-1.2$. Hal ini dimaksudkan agar kondisi aerobik yag dibutuhkan dalam proses pengolahan dapat tetap dipertahankan. Rasio panjang dan lebar kolam maturasi adalah (2-4) : 1 dengan waktu detensi antara 5 - 15 hari. Kolam maturasi pada IPLT Kendari memiliki kedalaman air 0.8 $m$ yang berarti sesuai dengan kriteria teknis yang dipersyaratkan namun dengan kedalaman yang lebih dangkal dapat memperkaya kolam dengan kandungan oksigen. Potongan kolam maturasi IPLT Kota Kendari dapat dilihat pada Gambar 7.

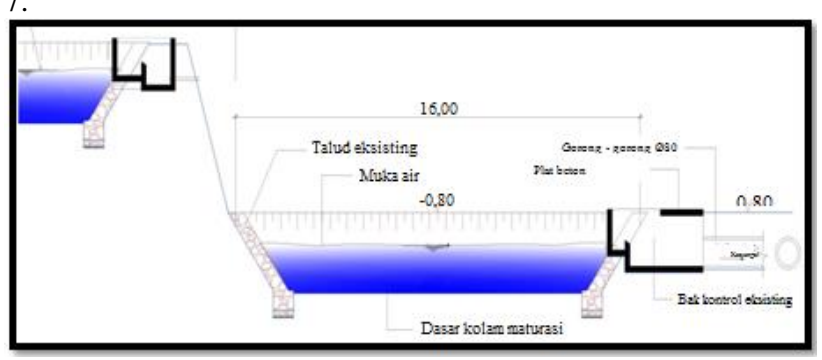

Gambar 7. Potongan Kolam Maturasi IPLT Kendari

Kelebihan dan kelemahan kolam maturasi Kota Kendari dapat dilihat pada Tabel 5 .
Tabel 5. Kelebihan dan kelemahan kolam maturasi Kota Kendari

\begin{tabular}{ll}
\multicolumn{1}{c}{ Kelebihan } & \multicolumn{1}{c}{ Kelemahan } \\
\hline - $\begin{array}{l}\text { Biaya operasi rendah } \\
\text { karena tidak }\end{array}$ & - Hanya mampu menyisihkan \\
menggunakan aerator & $\begin{array}{l}\text { BOD dalam konsentrasi yang } \\
\text { kecil. }\end{array}$ \\
- Mampu menyisihkan & - $\begin{array}{l}\text { Kondisi bangunan kurang } \\
\text { mikroba patogen }\end{array}$ \\
& $\begin{array}{l}\text { baik serta pinggiran kolam } \\
\text { stabilisasi ditumbuhi } \\
\text { tanaman liar }\end{array}$ \\
& \\
&
\end{tabular}

\section{e. Pengering Lumpur}

Unit pengering lumpur berfungsi untuk menampung endapan lumpur dari unit pengolahan biologis. Kriteria perencanaan berdasarkan petunjuk teknis perencanaan IPLT antara lain:

- Lebar sebuah bak

$$
=(4,50-7,50) \mathrm{m}
$$

- Panjang sebuah bak

$$
=(3-6) \times \text { lebar }
$$

- Ketinggian dinding bak

$=45 \mathrm{~cm}$ di atas pasir

- Tinggi jagaan

$=(15-25) \mathrm{cm}$

- Dinding bak bisa dibuat dari beton, pasangan bata dengan spesi semen

- Pipa pemberi yang membawa sludge ke tepi bak berdiameter $\geq 150 \mathrm{~mm}$. Pipa distributor mempunyai kriteria sebagai berikut:

- Dipasang di atas (di salah satu sisi) dinding memanjang tiap kompartemen

- Diameter $\geq 150 \mathrm{~mm}$

- Bila menggunakan bahan pipa dari PVC harus ditanam dalam dinding

- Pipa pembuang dipasang pada drainase bak dengan diameter minimal $15 \mathrm{~cm}$

- Kadar air lumpur kering optimal $=(70-80) \%$;

- Tebal lumpur kering di atas pasir $=(20-30) \mathrm{cm}$;

- Tebal lumpur basah di atas pasir $=(30-45) \mathrm{cm}$;

Bak pengering lumpur yang terdapat di IPLT Kendari memiliki lebar $7 \mathrm{~m}$ dan panjang $18 \mathrm{~m}$ (Gambar 6), yang berarti memiliki rasio perbandingan panjang dan lebar adalah 2,5:1. Bak pengering lumpur IPLT Kota Kendari dapat dilihat pada Gambar 8 .

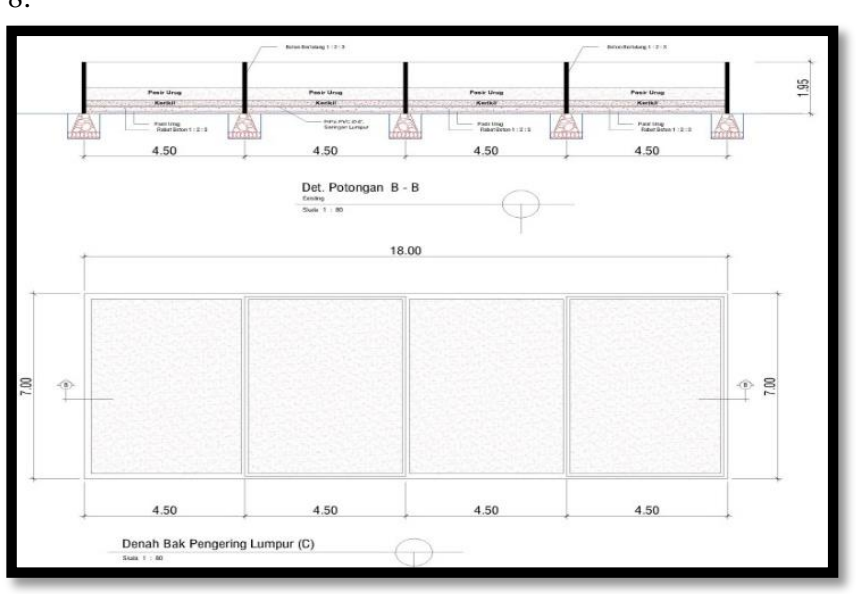

Gambar 8. Bak Pengering Lumpur IPLT Kendari

\subsection{Aspek Non-Teknis}

\subsubsection{Kelembagaan}

Keberhasilan kinerja dalam pengelolaan suatu IPLT maka diperlukan suatu organisasi dan manajemen pengelolaan IPLT. Organisasi dan manajemen pengelolaan IPLT ini dapat disebut juga sebagai kelembagaan IPLT, dimana kelembagaan IPLT ini mengatur dan mengawasi mulai dari tahap pembangunan hingga 
penggunaan IPLT tersebut. Untuk studi kasus IPLT Kendari, pengelolaan IPLT ditangani dibawah Dinas Pekerjaan Umum Dirjen Cipta Karya Kota Kendari. Struktur kelembagaan pengelolaan IPLT Kota Kendari dapat dilihat pada Gambar 9.

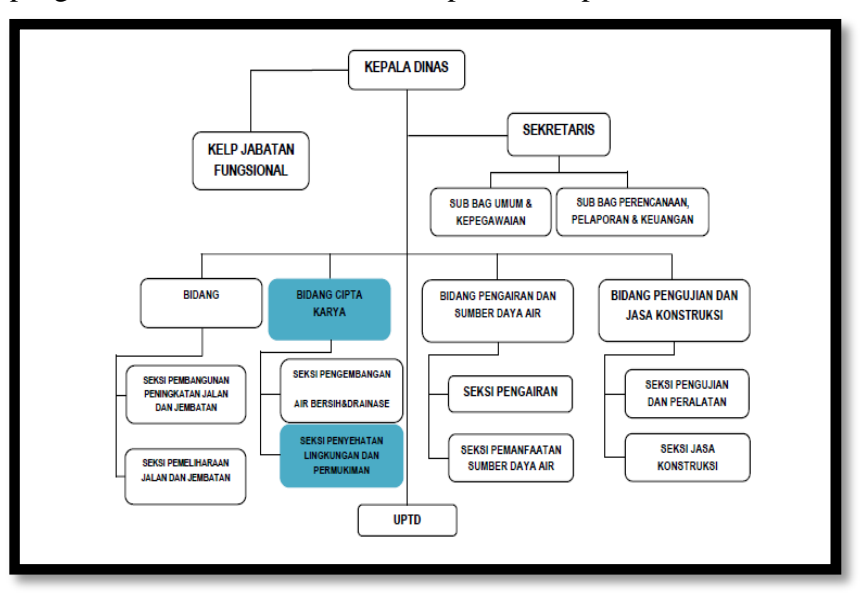

Gambar 9. Struktur Kelembagaan IPLT Kota Kendari

Pelaksanaan IPLT dilakukan dibawah Kementerian Pekerjaan Umum Dirjen Cipta Karya Melalui Satker PPLP Provinsi Sulawesi Tenggara. pengelolaan IPLT masih belum ditangani secara fokus oleh suatu lembaga yang memang hanya menangani IPLT, tetapi pengelolaan IPLT dimasukan ke dalam seksi kebersihan jalan dan drainase. Hal ini sangat berbeda, penanganan IPLT membutuhkan pengawasan yang tetap dikarenakan dari karakteristik lumpur tinja yang sangat berbahaya maka perlu penanganan yang khusus maka sebaiknya perlu ada lembaga tersendiri yang berfungsi sebagai pengelola IPLT, seperti UPTD atau bidang yang menangani khusus IPLT. Sehingga melalui lembaga tersendiri ini proses kerja yang terjadi di IPLT menjadi terarah dan terpantau sesuai dengan fungsi dari IPLT itu sendiri.

\subsubsection{Kebijakan}

Kebijakan atau regulasi sangat penting dimiliki dalam pengelolaan IPLT. Hal ini dikarenakan dengan adanya kebijakan atau regulasi yang bersifat sebagai payung hukum terhadap pelaksanaan pengelolaan IPLT yang ada, maka dengan demikian setiap yang dilakukan oleh IPLT akan diatur dan tunduk pada kebijakan atau regulasi yang ada. Kebijakan atau regulasi tersebut juga dapat digunakan sebagai dasar dalam mengambil keputusan pada setiap pelaksanaan yang akan dilakukan oleh IPLT. Pada Kota Kendari, peraturan daerah yang dimiliki berkaitan dengan IPLT adalah Peraturan Daerah Kota Kendari No. 4 Tahun 2007 Tentang Retribusi Pengangkutan Lumpur Tinja.

Peraturan ini mengatur tentang penetapan retribusi yang akan dibayarkan oleh pelanggan untuk mengangkut lumpur tinja. Dalam peraturan tersebut juga menjelaskan mengenai penetapan retribusi berdasarkan kelas pelanggan yang ada. Untuk penyedotan Domestik dikenakan tarif Rp. 400.000,- sekali penyedotan dan untuk Komersial dikenakan tarif penyedotan sebesar Rp. 600.000,- sekali penyedotan. Peraturan ini merupakan satu-satunya peraturan yang dimiliki oleh Kota Kendari dalam hal pelaksanaan IPLT yang ada. Untuk saat ini, Kota Kendari belum memiliki perda teknis yang mengatur mengenai pengelolaan air limbah domestik.

\subsubsection{Pendanaan}

Pembahasan mengenai pendanaan akan dimulai dari biaya atau investasi awal dari pembangunan IPLT. Investasi awal ini diperlukan dalam pembangunan instalasi pengolahan lumpur tinja beserta kelengkapannya di Kota Kendari. Dana investasi awal ini berasal dari dana APBN PLP sebesar Rp 1.700.000.000,Pendanaan yang ada juga mencakup mengenai iuran atau retribusi penyedotan tinja. Untuk iuran atau retribusi penyedotan tinja sudah diatur oleh Pemerintah Daerah Kota Kendari.

\section{KESIMPULAN}

Kandungan parameter Biologycal Oxygen Demand (BOD) pada lumpur tinja Kota Kendari masih jauh di atas ambang baku mutu yaitu sebesar 125,1 mg/L dari ambang baku mutu $100 \mathrm{mg} / \mathrm{L}$. Tingginya kandungan BOD IPLT Kota Kendari di sebabkan beberapa bangunan pengolahan sudah tidak dalam kondisi baik dan tidak terawat yang menyebabkan BOD tinggi sedangkan minyak dan lemak sebesar $1 \mathrm{mg} / \mathrm{L}$ memenuhi standar baku mutu yang telah ditetapkan berdasarkan Peraturan Menteri Lingkungan Hidup No. 05 Tahun 2014 sebesar 10 mg/L.

Unit pengolahan IPLT Kota Kendari yang terdiri dari tangki imhoff, kolam anaerobik, kolam fakultatif dan kolam maturasi dalam kondisi baik. Tetapi beberapa kolam tidak memenuhi kriteria berdasarkan Departemen PU 1998. Tangki imhoff hanya 3,7 m (kriteria 6-9 m), kolam anaerobik menimbulkan bau yang dapat mengganggu, tinggi air kolam fakultatif 2,0 m (kriteria 1,2 - 2,4 m). Menurut (Fitrijani Anggraini., dkk, 2014) terhadap hasil penilaian kesesuaian pengelolaan sistem IPLT Kota Kendari dengan menggunakan keempat aspek berdasarakan kriteria perancangan, teknologi, kualitas olahan dan fungsi instalasi dengan bobot 17,7 dengan kategori "buruk"..

\section{UCAPAN TERIMA KASIH}

Ucapan terima kasih kami sampaikan pada Program Studi Teknik Lingkungan atas pelaksanaan penelitian ini.

\section{DAFTAR PUSTAKA}

Departemen Pekerjaan Umum. 1998. Tata Cara Perencanaan IPLT Sistem Kolam, Petunjuk Teknis CT/AL/ReTC/001/98. Jakarta: Departemen Pekerjaan Umum Direktorat Jenderal Cipta Karya.

Direktorat Penyehatan Lingkungan Permukiman Dirjen Cipta Karya Kementrian Pekerjaan Umum. 2012. Materi Bidang Limbah.

Fajarwati, A. 2000. Penyaluran Air Buangan Domestik.

Fitrijani Anggraini., dkk, 2014. Peta Kondisi Instalasi Pengolahan Lumpur Tinja (IPLT) The Mapping Condition For The Treatment Of Faecal Sludge Installation. Jurnal Permukiman Vol. 9 No. 2 Agustus 2014 : 91-101.

Ginting, 2007. Sistem Pengelolaan Lingkungan dan Limbah Industri. Bandung.

Keputusan Menteri Negara Lingkungan Hidup Nomor 112 Tahun 2003 Tentang Baku Mutu Air Limbah Domestik.

Kristanto, 2007. Ekologi Industri.

Peraturan Pemerintah Nomor 82 Tahun 2001 Tentang Pengelolaan Kualitas Air dan Pengendalian Lingkungan.

Pokja Sanitasi Kota Kendari. 2012. Buku Putih Sanitasi Kota Kendari 
Soeparman, H.M. 2002. Pembuangan Tinja dan Limbah Cair, Suatu Pengantar Buku Kedokteran EGC. Jakarta.

Sugiharto. 1987. Dasar-dasar Pengolahan Air Limbah. UI-Press. Jakarta

Suharno, A.2012. Dasar-dasar Teknologi Pengolahan Air Limbah. Jakarta

Thcobanoglous. G. Theisen. H. 1993. Integrated Solid Waste Management. Engineering Principles and Management Issues. McGraw-Hill International Edition, New York.

Zulkifli, A.2014. Pengelolaan Limbah Berkelanjutan. Yogyakarta.

Direktorat Pengembangan Penyehatan Lingkungan Permukiman Dirjen Cipta Karya 